\title{
Chronic immune activation is the cause of aids: implication of treatment in the developing world
}

\begin{abstract}
Overwhelming number of evidence suggests that chronic immune system activation and dysregulation is responsible for progression into AIDS. Levels of activation markers on $\mathrm{CD}^{+}$and $\mathrm{CD}^{+} \mathrm{T}$ cells and other markers of activated immune response correlate with progression to AIDS. The uncontrolled inflammatory response has been associated with damage of lymphoid organs and the gastrointestinal mucosa; thus, further affecting $\mathrm{T}$ cell homeostasis and causing bacterial translocation, respectively. Immune system activation persists even after viral loads have been suppressed with antiretroviral therapy, which has been associated with increased morbidity and mortality of patients. On the other hand, natural primate hosts of SIV display very little immune activation and do not progress to AIDS. Several studies have been performed with immune suppressors and modifiers on HIV patients with varying degrees of success. The immune modifier that showed the most promise of being globally accessible and affordable was applying probiotic. Probiotic treatment studies demonstrated safety and efficacy in maintaining T cell homeostasis of HIVinfected individuals. The probiotic also has the potential of being genetically manipulated to increase its effectiveness. An effective probiotic treatment for HIV infections has the potential of being grown locally in resource limited regions and by the users themselves; therefore, reducing cost of HIV treatment and prolonging the health of HIV-infected individuals
\end{abstract}

Keywords: HIV; AIDS; Chronic Immune Activation; Cost-effective HIV treatment; Probiotics; Globally Accessible HIV treatment
Volume 2 Issue 2 - 2015

\section{Olga Malykhina}

Liberal Arts and Sciences department, Devry University, USA

Correspondence: Olga Malykhina, Devry University visiting professor, 3300 N Campbell Ave, Chicago, IL, 60618, USA, Tel 6|4-3|3-6343, Email omalykhina@gmail.com

Received: January 23, 2015 | Published: February 05, 2015

\section{Abbreviations}

HIV: Human Immunodeficiency Virus, AIDS: Acquired Immuno Deficiency Syndrome, SIV: Simian Immunodeficiency Virus, ART: Anti Retroviral Therapy, WHO: World Health Organization, HAART: Highly Active Anti Retroviral Therapy, GI: Gastro Intestinal, VNPs: Virologic Non-Progressors, SM: Sooty Mangabeys, AGM: African Green monkeys, LPS: Lipo Polysaccharide, HBV: Hepatitis B Virus, HCV: Hepatitis C Virus

\section{Introduction}

Recently we have experienced many breakthroughs in HIV treatment, such as stem cell transplants, that result in functional cure; however, none of these treatments will ever be accessible or of any benefit to places where HIV is most rampant, e.g. the developing world. Despite World Health Organization's (WHO) strides and successes in making antiretroviral therapy (ART) globally accessible there are still significant challenges to making ART accessible to the majority in low- and middle-income countries. ${ }^{1}$ Additionally, longterm-usage of antiviral drugs leads to drug-resistance, which increases the demand for better and more expensive drugs, further taxing the limited funds. ${ }^{2,3}$ The only effective way to increase HIV treatment availability and prolong the health of HIV-infected individuals in areas of limited resources is to make the treatment more accessible and affordable. The following review is designed to summarize the available evidence for causation of AIDS and the implication this causation has for cost-effective treatment.

\section{Chronic immune activation is the cause of AIDS}

There is a large body of evidence that suggests that chronic immune activation and dysregulation causes the progression to AIDS. In the early stages of HIV infection high levels of pro inflammatory cytokines are released in both plasma and lymph nodes. ${ }^{4}$ This is a normal physiologic response designed to destroy pathogens and restore homeostasis; however, in the case of HIV this robust immune response has been demonstrated to be ineffective in destroying HIV and even deleterious. Multiple reports have shown a link between poor prognosis for the infected patient and high level of activation markers on $\mathrm{CD}^{+}$and $\mathrm{CD}^{+} \mathrm{T}$ cells, regardless of the viral load $\mathrm{d}^{4-15}$ The Neopterin, a molecule secreted in increased amounts by activated monocytes and macrophages, is another immune system activation marker that is used to predict the development of AIDS. ${ }^{16,17}$

The danger of this chronic immune activation to T cells has to do with the cycle that $\mathrm{T}$ cells go through upon activation. Activation of $\mathrm{T}$ cells drives them to differentiate into antigen experienced cells, which then results in a large number of these cells undergoing apoptosis. The activated $\mathrm{CD}^{+} \mathrm{T}$ cells actually apoptose more rapidly that $\mathrm{CD}^{+} \mathrm{T}$ cells and thus get depleted more quickly., ${ }^{48-20}$ Additionally, the chronic immune system activation causes destruction and rapid ageing of the primary and secondary lymphoid organs and thus further interfering with normal $\mathrm{T}$ cell homeostasis. ${ }^{4,21} \mathrm{~T}$ cell activation persists even after viraemia has been suppressed to an undetectable level in HAART-treated patients. This persistent activation in HAART-treated patients has been associated with exhaustion of lymphopoiesis and subsequently increased morbidity and mortality. ${ }^{22,23}$

Previously the prevalent thought was that direct HIV infection of $\mathrm{CD}^{+}{ }^{+} \mathrm{T}$ cells caused their apoptosis and led to AIDS; however, the frequency of activated $\mathrm{CD}^{+} \mathrm{T}$ cells that undergo apoptosis greatly exceeds $\mathrm{HIV}$-infected $\mathrm{CD}^{+} \mathrm{T}$ cells..$^{24,25}$ Additionally, data demonstrated that the activation and dysregulation of the immune response is independent of HIV replication levels, suggesting factors other than viral replication are causing this pathological immune response and apoptosis. ${ }^{7}$ 
The chronic activation of the immune system not only proved to be damaging and ineffective in controlling HIV but it also creates a favorable environment for HIV replication. ${ }^{26-28} \mathrm{HIV}$ can only replicate in activated $\mathrm{CD}^{+} \mathrm{T}$ cells and the more activated the cells are the more likely HIV is to replicate and spread; thus, propagating the vicious and damaging cycle. Activation of $\mathrm{CD} 4^{+} \mathrm{T}$ cells also increases their CCR5 expression and thus making them better infection targets. ${ }^{29}$

The immune dysregulation that results during an HIV infection is further intensified by the massive loss of $\mathrm{CD}^{+} \mathrm{T}$ cells from the gastrointestinal (GI) tract, which occurs during the first few weeks of HIV infection. This depletion of $\mathrm{CD}^{+} \mathrm{T}$ cells at the GI tract is associated with disruption of the tight junctions and translocation of intestinal bacteria and bacterial products, which are presumed to exacerbate the hyper-immune response. ${ }^{21,28}$ Some studies suggest that it is the production of pro-inflammatory chemokines and cytokines that are responsible for disrupting the GI tract epithelial barrier and causing bacterial translocation. ${ }^{30,31}$

Some compelling evidence of how damaging this hyper-activation and dysregulation comes from studies of few HIV-infected individuals termed virologic non-Progressors (VNPs) ${ }^{21}$ The VNPs show signs of very low immune activation and experience stable levels of $\mathrm{CD}^{+} \mathrm{T}$ cells for many years, while displaying similar viral loads to AIDSProgressors. ${ }^{21,32,33}$ One study demonstrated that that these VNPs show a similar immune activation profile as natural hosts of SIV that do not progress to AIDS. ${ }^{33}$

\section{What studies with natural primate hosts reveal about the immune response and AIDS progression}

More evidence implicating chronic immune system activation in progression to AIDS came through studies of SIV-infected primates. Rhesus macaques also experience progressive depletion of $\mathrm{CD}^{+} \mathrm{T}$ cells and AIDS. ${ }^{34}$ The immune system in these primates, just like in humans, is also characterized by strong $\mathrm{T}$ cell activation. On the other hand, SIV-infected sooty mangabeys (SM) and African Green monkeys (AGM), the natural hosts of SIV, do not progress to AIDS and have minimal $\mathrm{T}$ cell activation despite evident viral replication. ${ }^{35-40}$ Interestingly, the SIV-infected $\mathrm{CD}^{+} \mathrm{T}$ cells of AGMs apoptose as rapidly as human $\mathrm{HIV}$-infected $\mathrm{CD}^{+} \mathrm{T}$ cells $;{ }^{41}$ thus, implying that the viral infection of these cells is not the main factor in causing the decline of $\mathrm{CD}^{+} \mathrm{T}$ cells.

The depletion of gut mucosal $\mathrm{CD}^{+}{ }^{+} \mathrm{T}$ cells was first perceived to be completely responsible for progression to AIDS. Studies with SMs revealed that mucosal $\mathrm{CD}^{+} \mathrm{T}$ cells also become depleted and spikes in LPS are seen during acute infection; however, after some time LPS levels become undetectable despite the fact that gut mucosal $\mathrm{CD}^{+} \mathrm{T}$ cells never become restored. ${ }^{42}$ The $\mathrm{SM}$ observation suggests that the $\mathrm{CD}^{+} \mathrm{T}$ cells are not solely responsible in preventing bacterial translocation and the loss of gut mucosal $\mathrm{CD}^{+} \mathrm{T}$ cells is not solely responsible for progression to AIDS. These studies with SMs imply that it is probably the hyper-active immune response with high levels of damaging cytokines that is responsible for compromising the gut mucosal barrier in HIV infected individuals.

\section{Modifying the immune response can prolong the health of HIV-infected individuals}

The overwhelming evidence implicating the immune hyperactivation in causing AIDS implies that if we modulate the immune response to reduce the degree of inflammation and immune activation we can prolong the health of infected individuals. A few studies have been performed studying the effects of several immune suppressors, immune modifiers, cytokine inhibitors, and cytokine boosters in HIV infected individuals with varying degrees of success and some failures. ${ }^{21}$ The most cost-effective immune modifier which showing some promise in improving $\mathrm{CD}^{+} \mathrm{T}$ cell levels and reducing inflammation is a probiotic supplement. The appeal of using Probiotics as a supplementary treatment for HIV infections lies in its low cost and potential to be synthesized in a yogurt form by the users themselves. This type of a treatment is ideal in low- and middleincome countries. A "yogurt project" in the Tanzanian community demonstrated the feasibility of locals making their own yogurt to provide to HIV-infected locals. ${ }^{43}$ If we can improve upon this yogurt treatment we can potentially improve the health and quality of life for millions.

Several studies that examined Probiotics' role in modifying the immune response in HIV patients demonstrated that Probiotics are generally safe and have a low risk of serious adverse effects; ${ }^{44-47}$ however, precautions should be exercised when dealing with immuno compromised patients. ${ }^{48}$ Another promising study examined the effects of Probiotics and Prebiotics supplementation in ART treated SIV-infected macaques. The supplementation with Probiotics and Prebiotics enhanced reconstitution and functionality of GI tract $\mathrm{CD}^{+} \mathrm{T}$ cells and reduced fibrosis of colon lymphoid follicles. ${ }^{49} \mathrm{The}$ degree of success between the probiotic studies are variable and this is most likely due to discrepancies in probiotic strains, probiotic concentrations, and Prebiotics supplementations used in different studies. Some of the earlier studies with Probiotics and allergies also suggest that different probiotic strains have different effects on the immune system..$^{50}$ More studies need to be done in order to establish the effective concentration, strain type, and probiotic supplementation.

It is possible that by genetically modifying Probiotics we can enhance its favorable effects on the immune system. Genetically modified Probiotics that secrete IL-10, an interleukin with antiinflammatory properties, have already been tested to be safe and effective in Crohn's disease clinical trial. ${ }^{51} \mathrm{~A}$ trial like this could be done to study the effects of genetically modified Probiotics secreting IL-7 on HIV infected patients. IL-7 is an interleukin known to increase survival of $\mathrm{CD}^{+}$and $\mathrm{CD}^{+} \mathrm{T}$ cells. Three clinical trials demonstrated an improvement in $\mathrm{CD}^{+}$and $\mathrm{CD}^{+} \mathrm{T}$ cell levels with IL-7 supplementation. ${ }^{21}$

Other possibilities in dampening and modifying the damaging immune response could be by administering particularly inflammatory HIV antigens in the context of a probiotic as an "oral tolerance" treatment. The term oral tolerance arose from the technique of using antigen ingestion for the purpose of modifying the immune response to that antigen ${ }^{52}$ The idea came from observations that immune response against ingested food antigens or bacterial flora is absent, suggesting that antigen presentation in the mucosa is modified to prevent unnecessary immune activation and inflammation. The original purpose of oral tolerance technique was to induce tolerance to auto antigens in autoimmunity disorders.$^{52}$ However, the term oral tolerance might be a misnomer since some cases have shown that tolerance to an antigen is not always induced, instead the immune response to that antigen is modified. ${ }^{53} \mathrm{~A}$ clinical trial tested the effects of feeding $\mathrm{HBV}$ and $\mathrm{HCV}$ antigens to $\mathrm{HBV}$ - and $\mathrm{HCV}$-infected patients demonstrated safety of this treatment, improvement in liver pathology, and the immune response to the virus. ${ }^{54,55}$ If a similar response can be observed in the context of HIV infections it would be feasible to create an HIV-antigen-secreting probiotic and use it as cost-effective HIV treatment.

\section{Conclusion}

In light of all the data pointing to immune hyper-activation and dysregulation being the culprit in transition to AIDS we need to shift 
more focus on developing a treatment that will modulate the damaging immune response and prolong the health of HIV-infected individuals. The probiotic treatment shows great promise in being a globally accessible and cost-effective means to extend the health of HIVafflicted individuals. In order to move forward we need to determine which probiotic strains, concentrations of Probiotics, and Prebiotics are most effective in modulating the damaging immune response. In addition, we should be open to the possibility of modifying the Probiotics to increase their positive effect on the immune system of an HIV-infected individual.

\section{Acknowledgements}

I would like to thank Samuel B. Florio for reading this manuscript and providing input.

\section{Conflicts of interest}

None.

\section{References}

1. WHO Global Update on HIV Treatment 2013: Results, Impact and Opportunities. 2013

2. Waning B, Kyle M, Diedrichsen E, Soucy L et al. Intervening in global markets to improve access to HIV/AIDS treatment: an analysis of international policies and the dynamics of global antiretroviral medicines markets. Global Health. 2010;6:9.

3. Pinheiro ES, Antunes OA, Fortunak JM A survey of the syntheses of active pharmaceutical ingredients for antiretroviral drug combinations critical to access in emerging nations. Antiviral Res. 2008;79(3):143-165.

4. Appay V, Sauce D Immune activation and inflammation in HIV-1 infection: causes and consequences. J Pathol. 2008;214(2):231-241.

5. Giorgi JV, Liu Z, Hultin LE et al. Elevated levels of CD38+CD8 $8^{+}$cells in HIV infection add to the prognostic value of low $\mathrm{CD}^{+} \mathrm{T}$ cell levels: results of 6 years of follow-up. The Los Angeles Center, Multicenter AIDS Cohort Study. J Acquir Immune Defic Syndr. 1993;6(8):904-912.

6. Liu Z, Cumberland WG, Hultin LE et al. CD8 $8^{+} \mathrm{T}-$ lymphocyte activation in HIV-1 disease reflects an aspect of pathogenesis distinct from viral burden and immunodeficiency. J Acquir Immune Defic Syndr Hum Retrovirol. 1998;18(4):332-340.

7. Giorgi JV, Hultin LE, McKeating JA et al. Shorter survival in advanced human immunodeficiency virus type 1 infection is more closely associated with $\mathrm{T}$ lymphocyte activation than with plasma virus burden or virus chemokine coreceptor usage. J Infect Dis. 1999;179(4):859-870.

8. Liu Z, Cumberland WG, Hultin LE et al. Elevated CD38 antigen expression on $\mathrm{CD}^{+} \mathrm{T}$ cells is a stronger marker for the risk of chronic HIV disease progression to AIDS and death in the Multicenter AIDS Cohort Study than $\mathrm{CD}^{+}$cell count, soluble immune activation markers, or combinations of HLA-DR and CD38 expression. J Acquir Immune Defic Syndr Hum Retrovirol. 1997;16(2):83-92.

9. Hazenberg MD, Otto SA, Van Benthem BH et al. Persistent immune activation in HIV-1 infection is associated with progression to AIDS AIDS. 2003;17(13):1881-1888.

10. Deeks SG, Kitchen CM, Liu L et al. Immune activation set point during early HIV infection predicts subsequent $\mathrm{CD}^{+} \mathrm{T}$-cell changes independent of viral load. Blood. 2004;104(4):942-947.

11. Wilson CM, Ellenberg JH, Douglas SD et al. $\mathrm{CD} 8{ }^{+} \mathrm{CD} 38+\mathrm{T}$ cells but not HIV type 1 RNA viral load predict $\mathrm{CD}^{+} \mathrm{T}$ cell loss in a predominantly minority female HIV+ adolescent population. AIDS Res Hum Retroviruses. 2004;20(3):263-269.

12. Giorgi JV, Lyles RH, Matud JL et al. Predictive value of immunologic and virologic markers after long or short duration of HIV-1 infection. $J$ Acquir Immune Defic Syndr. 2002;29(4):346-355.
13. Leng $\mathrm{Q}$, Borkow $\mathrm{G}$, Weisman $\mathrm{Z}$ et al. Immune activation correlates better than HIV plasma viral load with CD4 T-cell decline during HIV infection. J Acquir Immune Defic Syndr. 2001;27(4):389-397.

14. Sousa AE, Carneiro J, Meier-Schellersheim M et al. CD4 T cell depletion is linked directly to immune activation in the pathogenesis of HIV-1 and HIV-2 but only indirectly to the viral load. J Immunol. 2002;169(6):3400-3406.

15. Froebel KS, Raab GM, D'Alessandro C, Armitage MP, MacKenzie $\mathrm{KM}$, et al. A single measurement of CD38CD8 cells in $\mathrm{HIV}+$, longterm surviving injecting drug users distinguishes those who will progress to AIDS from those who will remain stable. Clin Exp Immunol. 2000;122(1):72-78.

16. Sheppard HW, Ascher MS, McRae B et al. The initial immune response to HIV and immune system activation determine the outcome of HIV disease. J Acquir Immune Defic Syndr. 1991;4(7):704-712.

17. Kanekar A Biomarkers predicting progression of human immunodeficiency virus-related disease. $J$ Clin Med Res. 2010;2(2):55-61.

18. Ferreira C, Barthlott T, Garcia S et al. Differential survival of naive CD4 and CD8 T cells. J Immunol. 2000;165(7):3689-3694.

19. Homann D, Teyton L, Oldstone MB Differential regulation of antiviral $\mathrm{T}$-cell immunity results in stable $\mathrm{CD}^{+}$but declining $\mathrm{CD} 4^{+} \mathrm{T}$-cell memory. Nat Med. 2001;7(8):913-919.

20. Foulds KE, Zenewicz LA, Shedlock DJ et al. Cutting edge: CD4 and CD8 $\mathrm{T}$ cells are intrinsically different in their proliferative responses. $J$ Immunol. 2002.168(4):1528-1532.

21. Paiardini $M$, Muller-Trutwin M HIV-associated chronic immune activation. Immunol Rev. 2013;254(1):78-101.

22. Sauce D, Larsen M, Fastenackels S et al. HIV disease progression despite suppression of viral replication is associated with exhaustion of lymphopoiesis. Blood. 2011;117(19):5142-5151.

23. Nwosu FC, Avershina E, Wilson R et al. Gut Microbiota in HIV Infection: Implication for Disease Progression and Management. Gastroenterol Res Pract 2014:803185.

24. Finkel TH, Tudor-Williams G, Banda NK et al. Apoptosis occurs predominantly in bystander cells and not in productively infected cells of HIV- and SIV-infected lymph nodes. Nat Med. 1995;1(2):129-134.

25. Herbeuval JP, Shearer GM HIV-1 immunopathogenesis: how good interferon turns bad. Clin Immunol. 2007;123(2):121-128.

26. Stevenson M HIV-1 pathogenesis. Nat Med. 2003;9(7):853-860.

27. Lackner AA, Veazey RS Current concepts in AIDS pathogenesis: insights from the SIV/macaque model. Annu Rev Med. 2007;58:461-476.

28. Brenchley JM, Price DA, Schacker TW et al. Microbial translocation is a cause of systemic immune activation in chronic HIV infection. Nat Med. 2006;12(12):1365-1371.

29. Douek DC, Brenchley JM, Betts MR, et al. HIV preferentially infects HIV-specific CD4+ T cells. Nature. 2002;417(6884):95-98.

30. Sankaran S, George MD, Reay E, et al. Rapid onset of intestinal epithelial barrier dysfunction in primary human immunodeficiency virus infection is driven by an imbalance between immune response and mucosal repair and regeneration. $J$ Virol. 2008;82(1):538-545.

31. Stockmann M, Schmitz H, Fromm M, et al. Mechanisms of epithelial barrier impairment in HIV infection. Ann N Y Acad Sci. 2000;915:293-303.

32. Choudhary SK, Vrisekoop N, Jansen CA, et al. Low immune activation despite high levels of pathogenic human immunodeficiency virus type 1 results in long-term asymptomatic disease. $J$ Virol. 2007;81(16):8838-8842. 
33. Rotger M, Dalmau J, Rauch A, et al. Comparative transcriptomics of extreme phenotypes of human HIV-1 infection and SIV infection in sooty mangabey and rhesus macaque. J Clin Invest. 2011;121(6):2391-2400.

34. Kaur A, Grant RM, Means RE, et al. Diverse host responses and outcomes following simian immunodeficiency virus SIVmac239 infection in sooty mangabeys and rhesus macaques. J Virol. 1998;72(12):9597-9611.

35. Silvestri G, Sodora DL, Koup RA, et al. Nonpathogenic SIV infection of sooty mangabeys is characterized by limited bystander immunopathology despite chronic high-level viremia. Immunity. 2003;18(3):441-452.

36. Norley S, Kurth R. The role of the immune response during SIVagm infection of the African green monkey natural host. Front Biosci. 2004;9:550-564.

37. Silvestri G, Fedanov A, Germon S, et al. Divergent host responses during primary simian immunodeficiency virus SIVsm infection of natural sooty mangabey and nonnatural rhesus macaque hosts. $J$ Virol. 2005;79(7):4043-4054.

38. Villinger F, Folks TM, Lauro S, et al. Immunological and virological studies of natural SIV infection of disease-resistant nonhuman primates. Immunol Lett. 1996;51(1-2):59-68.

39. Ansari AA, Onlamoon N, Bostik P, et al. Lessons learnt from studies of the immune characterization of naturally SIV infected sooty mangabeys. Front Biosci. 2003;8:1030-1050.

40. Chakrabarti LA, Lewin SR, Zhang L, et al. Normal T-cell turnover in sooty mangabeys harboring active simian immunodeficiency virus infection. J Virol. 2000;74(3):1209-1223.

41. Zhu Y, Gelbard HA, Roshal M, et al. Comparison of cell cycle arrest, transactivation, and apoptosis induced by the simian immunodeficiency virus SIVagm and human immunodeficiency virus type 1 vpr genes. $J$ Virol. 2001;75(8):3791-3801.

42. Gordon SN, Klatt NR, Bosinger SE, et al. Severe depletion of mucosa $\mathrm{CD}^{+} \mathrm{T}$ cells in AIDS-free simian immunodeficiency virus-infected sooty mangabeys. J Immunol. 2007;179(5):3026-3034.

43. Wenner M. A cultured response to HIV. Nat Med. 2009;15(6):594-597.
44. Gonzalez-Hernandez LA, Jave-Suarez LF, Fafutis-Morris M, et al. Synbiotic therapy decreases microbial translocation and inflammation and improves immunological status in HIV-infected patients: a doubleblind randomized controlled pilot trial. Nutr J. 2012;11:90.

45. Hummelen R, Hemsworth J, Changalucha J, et al. Effect of micronutrient and probiotic fortified yogurt on immune-function of anti-retroviral therapy naive HIV patients. Nutrients. 2011;3(10):897-909.

46. Schunter M, Chu H, Hayes TL, et al. Randomized pilot trial of a synbiotic dietary supplement in chronic HIV-1 infection. BMC Complement Altern Med. 2012;12:84.

47. Anukam KC, Osazuwa EO, Osadolor HB, et al. Yogurt containing probiotic Lactobacillus rhamnosus $\mathrm{GR}-1$ and L. reuteri RC-14 helps resolve moderate diarrhea and increases CD4 count in HIV/AIDS patients. J Clin Gastroenterol. 2008;42(3):239-243.

48. Boyle RJ, Robins-Browne RM, Tang ML. Probiotic use in clinical practice: what are the risks? Am J Clin Nutr. 2006;83(6):1256-1264.

49. Klatt NR, Canary LA, Sun X, et al. Probiotic/prebiotic supplementation of antiretrovirals improves gastrointestinal immunity in SIV-infected macaques. J Clin Invest. 2013;123(2):903-907.

50. Osborn DA, Sinn JK. Probiotics in infants for prevention of allergic disease and food hypersensitivity. Cochrane Database Syst Rev. 2007;(4):CD006475.

51. Braat H, Rottiers P, Hommes DW, et al. A phase I trial with transgenic bacteria expressing interleukin-10 in Crohn's disease. Clin Gastroenterol Hepatol. 2006;4(6):754-759.

52. Faria AM, Weiner HL. Oral tolerance. Immunol Rev. 2005;206:232-259.

53. Margalit M, Ilan Y. Oral immune regulation: a novel method for modulation of anti-viral immunity. J Clin Virol. 2004;31Suppl1:63-68.

54. Safadi R, Israeli E, Papo O, et al. Treatment of chronic hepatitis B virus infection via oral immune regulation toward hepatitis B virus proteins. Am J Gastroenterol. 2003;98(11):2505-2515.

55. Israeli E, Safadi R, Melhem A, et al. Induction of oral immune regulation towards liver-extracted proteins for treatment of chronic HBV and HCV hepatitis: results of a phase I clinical trial. Liver Int. 2004;24(4):295-307. 